\title{
Pollution of drinking water transported by corroded metallic pipelines
}

\author{
A.-Kh. M. Hussain, A. A. Sanoussi \& H. A. M. Hussain \\ Civil Engineering Department, Engineering College, \\ El-Fateh University, Libya
}

\begin{abstract}
Corrosion of metallic water pipelines is a function of the pipe's surrounding environment (soil and water). This means that it is important to know the physical and chemical characteristics of the pipe's surrounding environment. The corrosion of externally unprotected metallic water pipelines, particularly ductile iron pipes, in localities with aggressive soil conditions is becoming a significant problem: repair and replacement costs are high, and failures cause supply interruptions to customers and inconvenience to the public. Anti-corrosive protection for metallic water pipelines, their fittings and accessories is very important, because they may be attacked by corrosion with time. The tendency of a metallic substrate to corrode is a function of the surface characteristics of the metal and of the metal/protective film interface, the physical, electrical and electrochemical properties of the film, and the nature of the environment in which the pipelines system is placed.

In this work the authors have looked at the corrosion problems of metallic water pipelines and their control. The corrosive properties of water and soil environments are reviewed. Parameters affecting corrosion are discussed. The pollution of drinking water transported by metallic pipes caused by corrosion is discussed. The purpose of this work is to provide guidelines for materials selection in water and soil environments, and how the water pipelines can be protected against metallic corrosion.
\end{abstract}

Keywords: corrosion of metallic water pipelines, drinking water pollution, corrosive water, metallic water pipes. 


\section{Introduction}

Corrosion is one of the most important problems facing the water services industry and in the metallic piping systems. It is the most common threat to the performance and life of pipeline systems. Corrosion takes an even more significant toll in human life and safety [1-3]. It is the destruction of metal or metal alloy by chemical change (chemical reactions between a metal or metal alloy and its environment), the chemical reaction between a metal and acid, electrochemical change, or physical dissolution. The result of corrosion is the eating away of the metal surfaces of hydraulic components. Crevice corrosion occurs for steel bolts, and for drilled and tapped stainless steel pipes in aerated salt water. Copper pipeline systems carrying water can be attacked by pitting corrosion. It is more rapid and generalized when the PH-range is less than 7. Heavy metals in drinking water, such as lead $\left(\mathrm{Pb}^{++}\right)$, Copper $\left(\mathrm{Cu}^{++}\right)$, Zinc $\left(\mathrm{Zn}^{++}\right)$, and Iron $\left(\mathrm{Fe}^{++}\right)$, come from the corrosion of internally unprotected metallic water pipelines [4]. Municipal water must not only be treated for portability, but also for minimum corrosivity towards the distribution lines and the home plumbing system [4-6]. This can cause excessive leakage (losses of water quantity) past the sealing surfaces of the affected parts.

Accumulated corrosion and oxidation products on pipelines reduce their product, their strength, life and performance. Oxidation is the conversion of the surface portions of metal to oxide on heating in air or oxygen. It is caused by the chemical reaction of oxygen from the air with particles of water. Most products of oxidation are soluble in water and are acidic in nature, which can cause corrosion of parts throughout the system. Metal atoms in nature are present in minerals. The same amounts of energy needed to extract metal atoms from their minerals are emitted during the chemical reactions that produce corrosion. Corrosion engineering is the design and application of methods to prevent corrosion.

Losses of water from leaking pipelines have a high cost. These leaks have a corresponding hazardous effect on the health . Thousands of leaking pipelines must be repaired or replaced to prevent recurring losses of water and contamination of flowing groundwater. Corrosion of pipeline system built below groundsurface is a function of the nature of the surrounding soil and groundwater [7]. The soil in direct contact with the pipe will have the greatest influence on its behaviour over time which highlights the importance of knowing the physical and chemical characteristics of the pipe's immediate environment.

\section{Metallic pipe materials}

A pipe can be defined as a rigid or semi-rigid tube fabricated by many different methods and in many different materials (metallic and non-metallic). Types of metallic water pipes are Aluminium tubes, Copper tubing, Grey cast iron pipes, Ductile cast iron pipes, Steel pipes, Stainless steel pipes, Titanium tubing and Tungum tubes. The Aluminium, Copper, Stainless steel, Titanium and Tungum 


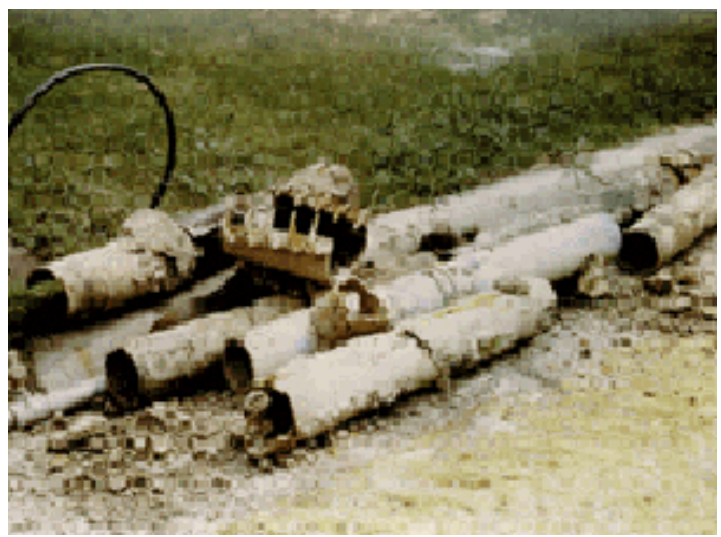

Figure 1: $\quad$ Corroded pipelines removed for replacement.

pipes are resistant to general corrosion. However, the Grey cast iron, Ductile cast iron and steel pipes have no resistance to corrosive atmosphere [8] as shown in Fig. 1. Ductile cast iron pipes are the type most widely used because of their rigidity, strength and durability in many kinds of soils. It is available in a wide range of tensile strengths. It is commonly used for hydraulic lines.

\section{Stages of corrosion}

The first stages of corrosion are indicated by rust spotting or the appearance of a few small blisters. Rust spotting is the very earliest stage of corrosion and in many cases is left unattended. Standards have been established for evaluating the degree of rust spotting and may be found in ASTM D 610-68 or (Steel Structures Painting Council Vis - 2). If the rust spots go unattended, a mechanism for further corrosion is provided. The definition of corrosion rate is the total metal loss divided by the period of time over which the metal loss occurred.

\section{Types of corrosion}

Corrosion is often identified with atmospheric rusting of iron base alloys. Corrosion attacks metallic water pipelines and can cause leaks and explosions in the pipe. Corrosion may be in the forms of pitting corrosion, definite holes, pockets, cavities, crevice corrosion, environmentally induced cracking, hydrogen damage, inter-granular corrosion, de-alloying, erosion - corrosion and graphitic corrosion. Different types of corrosion are seen in Fig. 1. Many metals and alloys have their own individual corrosion problem. Each corrosion problem has its own cure. Some corrosion can be controlled by electrical means (cathodic protection) or the application of a non-metallic barrier (coating). Such barriers should be barrier (100\% pore free) when used in highly aggressive water, and since this is rarely the case, they do not form a universal cure for 


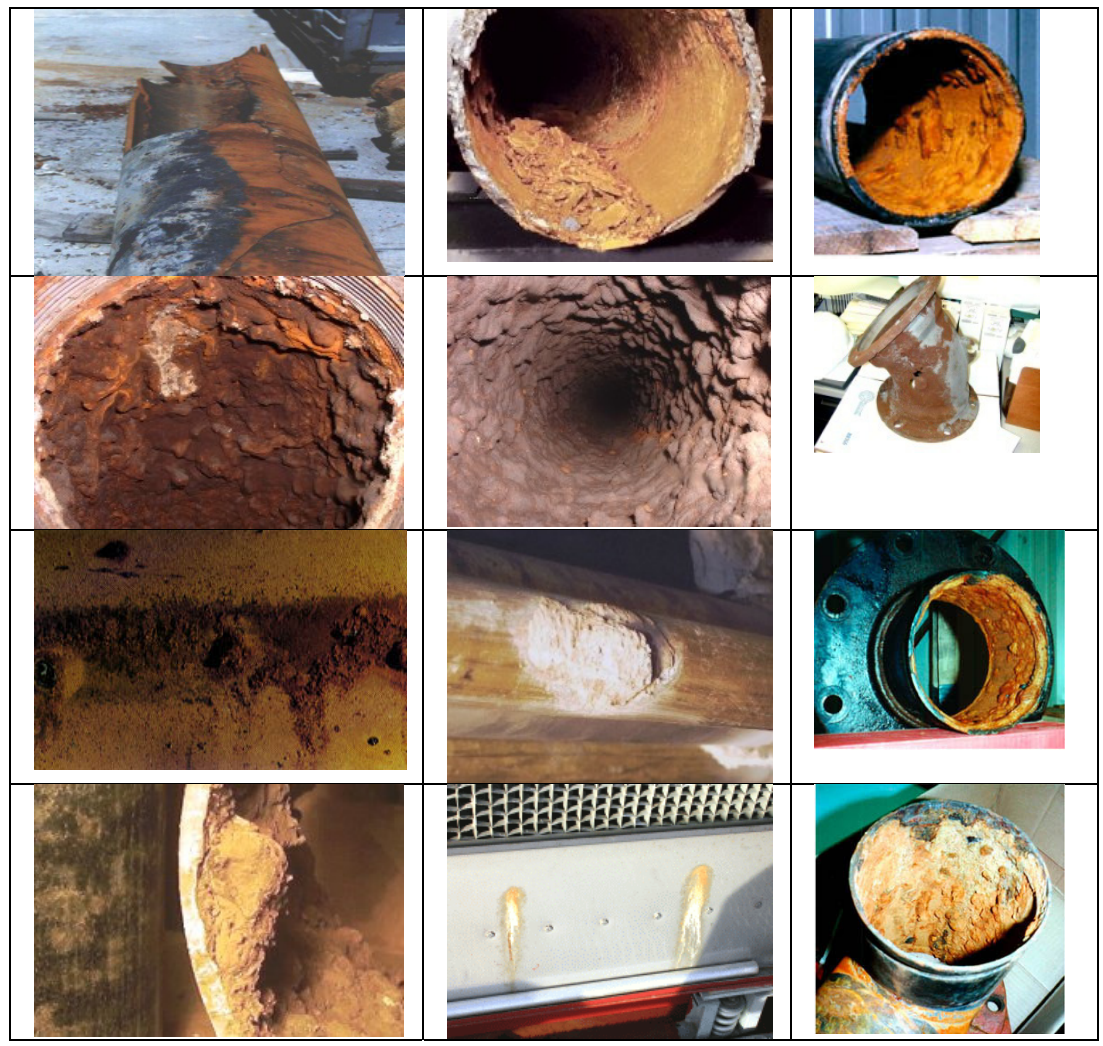

Figure 2: Different types of corrosion of metallic water pipelines.

metallic corrosion. Sometimes the metal generates its own barrier from corrosion products (metal oxide), the metal is then in the passive condition. Specific types of corrosion are discussed in the following paragraphs.

\subsection{Galvanic corrosion}

The main cause of deterioration in buried pipelines is galvanic corrosion. It is caused by the electrolytic action of a galvanic cell. It occurs for welded pipes, for carbon steel pipe flanges near the weld, and near the junction between dissimilar alloys. It decreases at points farther from the junction due to higher resistance through a longer electrolyte path. A local galvanic action is set up when there is a difference of potential between the areas on a metallic surface that is an electrolyte, as shown in Fig. 2. The resulting electrochemical reaction develops a potential difference between these metals. This causes one metal to be negative (anodic) and the other metal to be positive (cathodic). In a dry cell battery, the zinc case is the anode and the carbon rod the cathode. Now, when an external electrical circuit is completed, current flows from the zinc case into the electrolyte, taking with it particles of zinc. 


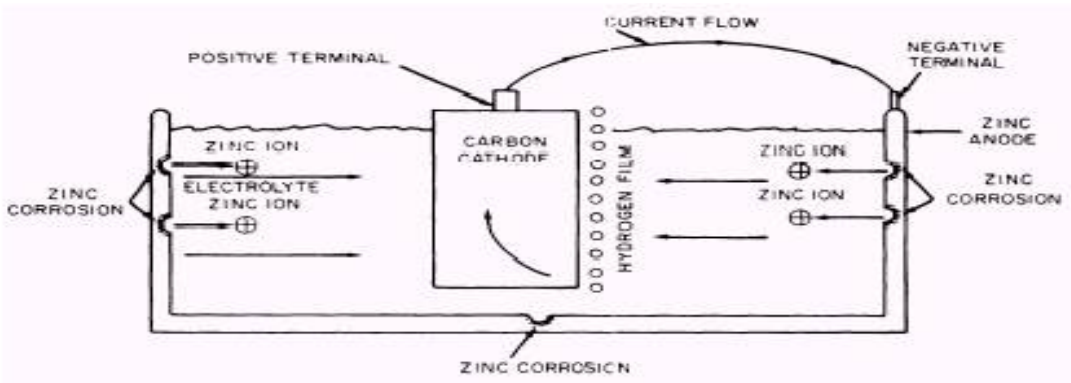

Figure 3: Galvanic cell showing internal galvanic action.

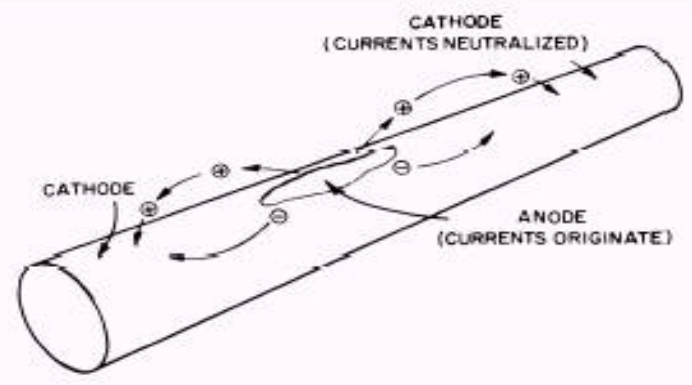

Figure 4: $\quad$ Pipe with corroding (anode) and noncorroding (cathode) areas.

\subsection{Corrosion due to mill scale}

The mill scale embedded in the walls of iron pipe during its manufacture is one cause of pipe corrosion. It actually becomes the cathodic area, the iron pipe the anodic area, and the moist soil the electrolyte as seen in Fig. 3. Current leaves the iron pipe wall and passes through the electrolytic soil to the mill scale. This electrochemical action causes severe pitting of the pipe metal at the anodic areas. Continued action of this type will eventually weaken the pipe to the extent of failure.

\subsection{Corrosion due to cinders}

Another type of corrosion occurs when iron pipe is laid in a cinderfill in direct contact with the cinders. The cinders and the iron pipe make up the dissimilar metals. The pipe forms the anodic area, the cinders form the cathodic area, and the highly ionized soil serves as the electrolyte. The current leaves the pipe through the soil to the cinders and returns to the pipe. Severe corrosion occurs at the points where the current leaves the pipe. 


\subsection{Corrosion due to dissimilarity of pipe surface}

This type of galvanic corrosion occurs when there are bright or polished surfaces on some areas of the pipe walls in contact with suitable electrolytic soil. These bright surfaces become anodic to the remaining pipe surfaces. In highly ionized soil, the polished surfaces corrode at an accelerated rate, thus weakening the pipe at that point.

\subsection{Corrosion due to different soil conditions}

This is a general corrosion problem, especially prevalent in highly alkaline areas. Corrosion currents leave the pipe wall and pass into compact soils and enter the pipe wall from light sandy soils. The intensity of the corrosion currents and the resulting rate of corrosion at the anodic areas of the pipe are directly proportional to the conductivity of the soil.

\subsection{Corrosion due to stray currents}

Direct current circuits that pass in and out of an electrolyte usually cause stray currents, many of which are a direct cause of corrosion. Corrosion does not occur at the point where the current enters the structure, because it is catholically protected. However, at the section where the current leaves the structure, severe stray current corrosion occurs.

\subsection{Corrosion due to bacteria}

Microbiological corrosion is another distinct type of corrosion caused by electrolytic or galvanic cell action [9, 10]. It is the deterioration of metals by corrosion processes that occurs as either a direct or an indirect result of the metabolic activity of bacterial organisms, particularly in water or soil environments. Microbiological corrosive action in the soil is due to physical and chemical changes in the soil caused by the presence of these organisms close to the metal surface in stationary slimy deposits produce corrosive substances, such as, carbon dioxide, hydrogen sulphide, ammonia, and organic and inorganic acids. These corroding substances are found only in the locality of the colony and may be undetected in the surrounding water or soil. Bacteria that cause corrosion in this way need to produce only small amounts of corrosive products for localized attack. However, colonies of bacteria that do not produce corrosive products may act as a protective film around the metal, causing unequal distribution of electrical potential, which gives rise to local anodes and cathodes. In this way, the production of local cells will cause increased corrosive action. Biological corrosion is extremely difficult to control, since the organisms are very resistant to normal methods of sterilization. Probably the most logical method to reduce microbiological corrosion is by the use of some barrier coating between the environment and the metal. Some bacteria are responsible for the production of active galvanic cells. These bacteria are mostly found in highly waterlogged, sulphate-bearing, blue clay soils. The bacteria concentration, as 
well as the corrosion rate, varies considerably with the different seasons of the year. Cast-iron and steel pipes are corroded mostly by sulphide production.

\subsection{Dezincification}

This is a selective type of corrosion that occurs in copper and zinc alloys. When alloys of this kind (brasses) are exposed to this type of corrosion, the zinc dissolves out of the alloy and leaves only the copper.

\subsection{Graphitization}

Another type of compositional corrosion is graphitization or graphitic softening. It is a form of disintegration that attacks buried grey cast iron water pipes and their fittings after many years of exposure in soil and groundwater. Cast iron is an alloy made of iron and carbon, the carbon being in the form of graphite. When cast iron with such a composition is subjected to graphitization, the iron dissolves out and leaves only the graphite. This action leaves cast-iron pipes and other similar equipment weakened mechanically. However, after graphitization corrosion occurs, the graphite pipe may last for many years if it is not subjected to any mechanical forces or sudden pressures. The action of this type of corrosion is similar to dezincification.

\subsection{Hydrogen embrittlement}

This is a term applied to metal that becomes brittle because of the action of some form of corrosion that causes the formation of hydrogen on its surface. When hydrogen forms on the surface of steel, the action of the hydrogen may form blisters or actually embrittle the metal. Hydrogen liberated near the surface of steel in an electrolyte will diffuse into the metal quite rapidly. The hydrogen picked up by the steel is in an atomic state and causes the steel to become brittle. When the production of atomic hydrogen on the surface of the metal stops, the hydrogen leaves the metal in a few days and the metal again regains its original ductility.

\subsection{Stress fatigue of metals (corrosion affects metals that are under stress)}

The action caused by stresses on a pipeline or structure is due to the shifting of the various rocks and soils of the earth. Usually a complete pipeline is not under stress; certain sections are under stress while adjacent sections are not. Because of these pressures and strains, localized electrochemical action takes place. The section of the pipe or structure under stress becomes anodic, whereas the unstressed sections become cathodic. In this way, the pipe under stress begins to corrode and weaken because of the action of corrosion.

\section{Pipe performance and selection}

A range of performance parameters have to be considered when selecting a pipeline material, so that the final decision based on economic and availability 
factors can be made. These parameters are compatibility of pipe with media and environment (its resistance to corrosive atmosphere), pipe bore size, strength of pipe for internal and external pressure, temperature of media and environment, flexibility and bend radius, weight and compactness, expansion and compatibility of pipe with jointing method. Where steel pipes have to be used from a strength requirement, a greater use of stainless steels is being made in the smaller pipe bore sizes. Where larger steel pipes have to be used they can be lined with a coating of PTFE (Polytetra- fluorocthylene), which can be extended over the flange faces, so that the media doses not come in contact with the steel pipe [12-14]. Typical manufacturer's range of pipe sizes showing the thickness of the PTFE lining in the range of $2.8 \mathrm{~mm}$ to $5 \mathrm{~mm}$. For environmental protection of the external surfaces of the pipes, the external surfaces of the pipe can be coated with a material which is resistant to the working environment, before being installed. Specially developed plastic coatings have greatly increased the range of basic materials which can be used for water pipelines in a wide range. The main benefits obtained from such coatings are protection against corrosion and chemical attack, increased abrasive resistance and non- toxicity. Plastic coatings also lessen the risk of impact damage, reduce erosion and in certain instances improve the flow characteristics of some piping systems. Coatings for general use include Polyvinyl chloride (PVC), Polyethylene (PE), and Polypropylene and nylon.

\section{Conclusion}

It is known that more than half of all corrosion problems could be avoided by direct application of established knowledge. Each corrosion problem has its own cure. To prevent excessive corrosion, good inspection procedures and preventative maintenance practices are required. Proper design consideration are also necessary, as well as, selection of the proper coating system. Regular inspections of coating should be conducted. Since corrosion of substrates under coatings takes place in stages, early detection will permit correction of the problem thereby preventing ultimate failure. Sanitary engineers are responsible for minimizing the direct and indirect costs and risks to the public from corrosion. Causes of corrosion have to be known. Methods of prevent and minimize its effects have to be practically followed.

\section{References}

[1] Walker, R., Corrosion Is Pollution. Uni-Bell PVC Pipe News, 1995, 18 (2).

[2] Rajani, B., McDonald S. and Felio G., Water Mains Break Data on Different Pipe Materials for 1982 and 1993. NRC Canada Report, August 1995.

[3] USEPA, Water on Tap. A Consumer's Guide To The Nation's Drinking Water, US Environmental Protection Agency, Office of Water (4601), July 1997. 
[4] Lee R.G., Becker, W.C. and Collins, D.W., Lead at the Tap. Sources and Control J. Am. Water Works Assoc. 81(7), 1989, pp. 52-62.

[5] Plishka M.J. and Shenkiryk M., Chemical Cleaning Process for Water Systems. Water Engineering \& Management, March 1996, 143(3).

[6] Reiff F., Biofilm in Water Distribution Systems. Drinking Water \& Health, A Publication of the Public Health Advisory Board to the Chlorine Chemistry Council ${ }^{\circledR}$, Fall 1996, 3(4).

[7] Jakobs J.A. and Hewes F.W., Underground Corrosion of Water Pipes in Calgary. Canada, Materials Performance, May 1987, 26(5).

[8] Millette J.R., Hammonds A.F., Pansing, M.F., Hanson E.C. and Clark A., Aggressive water: Assessing the Extent of the Problem. J.Am. Water warks Assoc. 72(5) (1980): 262-266.

[9] Simgley J.E., The Search for a Corrosion Index. J.Am. water Works Assoc. 73(11) (1981): 579-582.

[10] Kriewall G., Tracking Bacteria Not Easy. Times Herald, August 22, 1997.

[11] Ruda T., Microbial Regrowth and Distribution System Management. Opflow- American Water Works Association, August 1997, 23(8).

[12] Merrill D.T. and Sanks R.L., Corrosion Control by Deposition of $\mathrm{CaCO}_{3}$ Films. J. Am. Water Works Assoc. 69(11) (1977): 592- 599; 69 (12) (1977): 634- 640; 70(1) (1978): 12-18.

[13] Langelier W.F., The Analytical Control of Anticorrosion Water Treatment. J. Am. Water Works Assos. 28 (1936): 1500.

[14] Schock M.R., Understanding Corrosion Control Strategies for Lead, J. Am. Water Works Assoc. 81(7) (1989): 88-100. 